\title{
The Role of Gender and Income Level in the Relationship Between Ego Functions and Resilience
}

\author{
Firdevs Savi Çakar (Corresponding author) \\ Department of Education Sciences, Burdur Mehmet Akif Ersoy University \\ İstiklal Yerleşkesi, Burdur, 15100, Turkey \\ Tel: 90-248-213-4292Ｅ-mail: firdevssavi@hotmail.com
}

Received: January 17, 2020 Accepted: February 16, 2020 Published: February 23, 2020

doi:10.5296/jei.v6i1.16276 URL: https://doi.org/10.5296/jei.v6i1.16276

\begin{abstract}
This study is a research conducted in the relational screening model aiming to examine the intermediary role of gender and income in the relationship between ego functions and resilience. The research was conducted with 251 participants who volunteered to participate among fourth-graders attending different undergraduate programs of a university. $49.8 \%$ of the participants were female, and $50.2 \%$ were male; the mean age was 23.6 years. The Resilience Scale for Adults and Ego Functions Assessment Scale were used as data collection tools in the research. Descriptive statistics, Pearson Correlation Coefficient and Multiple Regression Analysis were used in the analysis of data. Consequently, whille resilience did not differ significantly in terms of gender, evaluating the truth from ego functions were found higher in men, and stimulant threshold and judgment were found to be higher in women. While it was determined that ego functions predicted resilience at a significant level, the intermediary role of gender and income level was not found in the relationship between ego functions and resilience. Consequently, it may be useful to consider ego functions as a variable in improving the resilience of young individuals.
\end{abstract}

Keywords: Ego functions, Resilience, Gender, Income level, Young

\section{Introduction}

Resilience is regarded as both a form of coping and enhanced functionality in the face of difficulties in many areas (Masten \& Cicchetti, 2012). Resilience is the ability to make sense of things, to learn from even the most negative situations and to find the power to continue without losing faith and perseverance (Southwick et al., 2014). Focusing on developmental psychopathology and investigating resilience have become a necessity due to the importance of maintaining the harmony of individuals despite the increasing life events and social 
conditions such as violence, poverty, stress, trauma, deprivation, and oppression (Gitterman, 1991). To maintain and strengthen the mental health of young people during the university period, it is important to increase protective factors, reduce the impact of risk factors and eliminate the problems experienced. In this context, the resilience of young people is one of the characteristics that need to be improved.

\section{Literature Review}

\subsection{Resilience}

Resilience (Tugade \& Fredrickson, 2002) or ego resilience (Block \& Kremen, 1996) is an individual's ability to adapt successfully to ever-changing situations, desires and environmental demands, and to adapt his behavior to various situational conditions (Block, 2002). Ego resilience is the highest personality component of the self and can, therefore, be considered as a personality trait or as a relatively stable cognitive structure or diagram. Therefore, ego resilience is a measure of the flexibility of psychological processes that take shape over time and lead to durability (Philippe et al., 2009).

Resilience is defined as the ability to overcome distress and stress (Zautra, Hall, \& Murray, 2010), which expresses inner and external good harmony when under difficult conditions (Masten, 2001). Resilience is a phenomenon that arises as a result of the apparent interaction of protective factors that contribute to a healthy adaptation with existing risk factors (Windle, 1999). It is indicated that resilient people are often not frustrated in the face of stress-generating events, but can successfully maintain their interactions with the environment; on the contrary, they can recover more quickly and even overcome adversity and adverse environmental conditions each time by getting stronger (Henderson \& Milstein, 1996). Resilience, considered as an important life skill, is seen as a protective mechanism that encourages an individual to cling to life and learn to cope with difficulties (Masten, 2001).

One of the two main factors emphasized in the concept of resilience is the ability to quickly balance and recover to get rid of these events in response to stressful life events and to return to a healthy starting state. The second factor is sustainability, referred to as the ability to continue to react sturdily in other stressful situations as a result of healthy responses to stressful life events (Reich, 2006). Besides, risk factors and/or difficulties, adaptation and coping, competencies and protective factors are important components in resilience; rather, they describe a dynamic development process associated with maintaining positive harmony under life-threatening conditions (Luthar, 2006). An individual's strengths and virtues, level of optimism, coping, social support, life goals, thought control skills are variables associated with resilience (Seligman, 2011). Resilience is a structure containing protective factors (competencies, abilities, and skills) included in the individual (individual-level factors), family and friend network (social-level factors) and the entire school environment and society (social-level factors) (Masten, 2001).

In a meta-analysis study conducted to determine important factors in the development of resilience, it was found that the greatest impact on resilience was protective factors, moderate effect included risk factors, and the smallest effect of the medium effect were demographic 
factors (Lee et al., 2013). People with high resilience, who have positive relationships, are resourceful in solving problems and have motivated to improve themselves, are open to social change and participate in activities, have faith and those who can extract meanings and benefits from the difficulties, traumas, and sorrows in their lives. These people can also return from difficulties by creating positive emotions on their own after a negative experience (Masten \& Cicchetti, 2012). In connection with positive youth development (Catalano et al., 2004), to adapt very well despite the risk, young people can be assisted in adapting to live stressful and risky life by increasing both internal and external protective factors (Spencer, 2006). Therefore, resilience can be used to improve many psychopathologies as well as to protect and strengthen mental health (Masten \& Cicchetti, 2012), and it is seen that resilience can be focused on young people in the university period for similar purposes.

\subsection{Ego Functions}

While the ego reveals how the way a person perceives himself and the world has a huge impact on developmental, environmental traumas and interactions between them (Fleischer \& Lee, 2013), it is the structure that facilitates self-regulation as the functioning self (Auchincloss \& Samberg, 2012). Freud used the word ego for the self; he proposed a three-factor model to explain the mind: id, ego, and superego. Id is the primitive part of the mind that wants desires and needs to be met immediately; ego is the rational part of the mind and provides an individual's adaptation to external environment, ego decides whether id's wishes can be met or under what conditions they can be realized, and superego tries to provide control over ego similar to the control of the ego over id. Ego is a structure that develops by differentiating from the structure of id. Freud suggests that the ego is one of the specific functions of the spiritual apparatus, and the regulator of the ego spiritual structure, the part of the balance and harmony (homeostatic). Ego is the basic structure that shapes all our relations with the outside world and is the roof for our sense of identity (Freud, 1989).

Traditionally, ego-oriented evaluation offers a biopsychological perspective that examines both an individual's functionality and the internal and external forces affecting them (Fleischer \& Lee, 2013). Contemporary approaches, on the other hand, emphasize the interactions between the elements shown to have a huge impact on how the individual perceives himself and the world. The ego is also an organization of functions that share the role of mediator between instincts and the outside world as a common point, and the ego is a mediator between the lower self and the outside world. Ego functions help in clinically defining emerging symptoms such as dissecting thought processes, sexual or aggressive movements, withdrawal from society, inadequate judgment and reality testing, and ego functions provide a sense of identity to a person (Tsarfati, 2017). Defensive functions of the ego exist to help the self-understand contradictions, and these are mechanisms that protect the individual from internal and external threats that can lead to anxiety (Goldstein, 1995).

According to Ericson, the ego is a very powerful and independent part of the personality. It works towards the goals of establishing one's identity and satisfying the need to establish dominance over one's environment. The first function of the ego is to create and maintain a sense of identity. Ericson described identity as a complex intrinsic state, including feelings of 
individuality and uniqueness, as well as feelings of integrity and continuity with the past and the future. The ego is the basic structure that ensures the integrity and continuity of one's identity. A strong ego structure is needed to adjust our relations with the outside world and takes responsibility for our actions, to be aware of what we can and cannot do, and to accept all of this (Jerry, 2006). It is indicated that the evaluation of the basic functions of the ego helps identify the strong and weak characteristics of the self (Bellak \& Meyers 1975).

Ego Psychology Theory, on the other hand, has been suggested from the beginning that ego is a different structure from Id, and this theory distinguishes from classical psychoanalysis with this hypothesis. In this theory, the ego is recognized for the first time as a structure that regulates the whole sense of identity and has a portion independent of unconscious conflicts, and the two main characteristics of the ego were discussed as "defense" and "harmony". According to the theory, the basic functions of the ego are listed as follows: Evaluating the truth, being aware of the appropriateness and possible consequences of an intended behavior, intuition of the world and self-truth, regulation and control of impulses and emotions, regulation of relationships with people, ability of thought processes to direct thought and ensure the continuity of thought, awareness of pre-conscious and unconscious content, and increased creative thinking and adaptability, the use of defense mechanisms, the nature of the response to stimuli at levels, perception, intuition, sensation, thinking, language, motor development, insight, learning, intelligence, memory, habitual behavior, learned complex skills, hobbies, and regulation of interests, the integration of attitudes, values, emotions, behavior, and self-representations, the degree of existing interaction with the environment, individual's expectation of success (Freud, 1986).

It is indicated that the evaluation of the basic functions of the ego helps identify the strong and weak characteristics of the self. These functions are defined as follows (Bellak \& Meyers, 1975):

Testing reality primarily refers to the primary autonomous functions of the ego, such as memory and perception, and then the ego's capacity to objectively evaluate and judge the outside world. A sense of reality emerges simultaneously with the development of the ego, it expresses the capacity to distinguish between own bodily sensations and then an external reality. Judgment refers to the consequences of an individual's actions, such as perceiving danger, feeling impropriety or an objection from others, and avoiding physical harm. Control and regulation of instinctive impulses are closely related to the development of the ego's capacity to test the truth and its regulatory role between id and the outside world, which preserves the integrity of the individual. Object relationships are the ego's capacity to build mutually insatiable relationships. The ability to establish healthy relationships is an important function as the capacity to establish a relationship with others. Thought processes are related to thinking and communicating well, attention, concentration, language, and memory. Regression in ego service also enables adaptation to new configurations and creative integrity. The stimulus barrier includes the ability and adaptation of individuals to regulate stimuli. Autonomy is a state of autonomy, conflict, acting independently of influences and impulses. It explains the stimulation of obstructive defensive reactions by the ego. Competence, according to its sources, relates to the capacity to dominate an individual's environment and is also one 
aspect of regulating self-esteem. Therefore, it includes object relationships, a sense of reality and reality test. Synthesis indicates the capacity to integrate various aspects of ego functions. It includes the capacity of the ego to combine, organize and connect the different impulses, tendencies, and functions of the ego in personality to enable the individual to think, feel, and act in an organized and oriented manner. In short, the synthesis function is related to the whole organization and functioning of ego within the self-system, and consequently, refers to the cooperation of functions belonging to the ego or not in its functioning. While many important functions of the ego are mentioned, it may be important to examine the ego functions of young people in university and to determine the variables that are effective in their relationship to resilience.

It has been observed that people with a positive worldview seek more support from their environment when they experience stress or disaster, they can produce solutions to their problems and have the capacity to see opportunities in difficult situations (Wang, 2009). It is indicated that individuals with resilience have an energetic approach to life, are curious, open to new experiences and have interpersonal insight; with a positive perception of the environment, individuals' ability to see opportunities in difficult situations and to find solutions to problems also increases (Tugade \& Frederickson, 2002). Today, the acceptance of resilience as a stress-protecting and health-enhancing factor that contributes to quality of life and well-being (Masten \& Obradovic, 2006), university students' resilience as a very important variable predicting adaptation to university life (Yalım, 2007) are all significant for the young people in terms of emphasizing its contribution to psychological growth and development (Nolte et al., 2011). Therefore, examining other variables related to resilience may contribute to future studies to be conducted on this subject.

In studies on resilience, positive emotional and cognitive factors (Kararrmak, 2007), perceived social support (Terzi, 2013); self-esteem, positive emotions and the focus of control (Karaırmak \& Siviş-Çetinkaya, 2011), intrinsic protective factors (optimism, self-sufficiency, problem solving-oriented coping strategy) (Terzi, 2008) were examined. Besides, Gürgan (2006) examined the effect of the resilience group counseling program on resilience levels of university students. In another study, life satisfaction and depressive symptoms of resilience were examined through positive cognition about the self, the world and the future (Erarslan, 2014).

In resilience studies, gender and income variables were studied often and show different results (Arastaman \& Balcı, 2013; Çiftçi Arıdağ \& Ünsal Seydooğulları, 2019; Gürgan, 2006; Orthner, Jones-Sanpei \& Williamson, 2004; Savi Çakar, 2018; Sun \& Stewart, 2012). This study aims to contribute gender and income role on ego functions and resilience levels of young people directly and indirectly.

Accordingly, this study aimed to examine the role of gender and income level in the relationship between ego functions and resilience in young people. For this purpose, the following sub-problems were created:

(1) Do resilience and ego functions differ significantly in terms of gender? 
(2) Is there a significant correlation between resilience and ego functions?

(3) Do ego functions predict resilience at a significant level?

(4) Do gender and income levels have a role in the relationship between ego functions and resilience in young people?

\section{Method}

\subsection{Research Model}

This study was patterned in the relational screening model, which aims to examine the role of gender and income level in the relationship between ego functions and resillience in university students. Relational screening models are research models that aim to determine the presence and degree of change between two or more variables. Relationships found through scanning cannot be interpreted as a true cause-and-effect relationship; however, by giving some clues in that direction, it can give useful results in predicting the other if the situation in one variable is known (Karasar, 2013).

\subsection{Study Group}

The research was conducted with 251 participants who volunteered to participate among fourth-graders attending different undergraduate programs of a university. $49.8 \%$ of the participants were female, and 50.2\% were male; $29.2 \%$ of them stated that their family's monthly income level was low; $43.3 \%$ of them reported a moderate level of income, and $27.5 \%$ of them reported high level of income. The mean age of the participants was 23.6 years. $93.2 \%$ of the participants' parents were alive; $5.2 \%$ of them had only their mothers, and $1.6 \%$ of them had only fathers. Besides, it was determined that $80.9 \%$ of the participants had a nuclear family, $13.9 \%$ of them had large families, and $5.2 \%$ of them had deteriorated family integrity (divorce, death, etc.).

\subsection{Data Collection Tools}

The Personal Information Form was included consisting of information about participants' gender, income levels, age, and parental life and information about their home family structure.

Resilience Scale for Adults: developed by Friborg et al. (2003) (cited in Basım \& Çetin, 2011), the scale was revised in 2005, and it was adapted into Turkish by Basım \& Çetin in 2011, with reliable and validity studies applied. There were 33 items on the scale with incomplete statements, each incomplete statement was requested to be completed with negative and positive options. Between negative and positive judgments in the options, choices were evaluated with 5-item Likert points. The scale consisted of 6 dimensions including "self-perception, perception of the future, structural style, social competence, family harmony, social resources". In this study, the Cronbach Alpha coefficient of the scale was 0.84; coefficients of sub-dimensions varied from 0.60 to 0.74 (Basım \& Çetin, 2011).

Ego Functions Assessment Scale: There were 120 items on a scale developed by Bellak (1966) and revised by Bellak et al. (1973) (cited in Çevik, 2011), and the scale was adapted to the 


\section{Ml Macrothink}

Turkish language by Çevik (2013). Total score of the scale was not taken, and items grouped under 12 dimensions (the ability to evaluate reality, judgment, thinking processes, creativity, sense of reality, object relationships, control of instincts, functioning of defenses, autonomous functions, stimulus threshold, synthesis ability, dominance/success) were collected separately. Because items in sizes were different when calculating dimension points to understand which ego function was higher, the total points of the item were divided by the number of items, and scores were obtained in the range of 0 to 3 . In this study, it was determined that Cronbach's Alpha coefficients of dimensions varied between 0.63 to 0.78 .

\subsection{Data Analysis}

In the analysis of the data, it was determined that the scores showed normal distribution since the skewness coefficient remained within \pm 1 limit in the normality test of scale scores. The t-test for Independent Samples was used to determine whether resilience and ego functions in young people varied in terms of gender. Pearson Correlation Coefficient was used in correlation tests between scale scores; progressive multiple regression analysis was used to determine the effect of ego functions on adult resilience) and the role of gender and income level in this effect. In Regression Analysis, the gender variable was encoded as female 0 and male 1. In the first stage of regression analysis, independent variables were included in the model in blocks, and their contribution to the variance of the dependent variable was examined. In the second stage, gender and level were included in the model, and the change in variance was examined. Whether gender and income level have a significant effect on the relationship between independent and dependent variable according to the variance difference in the first model and the second model was evaluated by the level of statistical significance in the variance change. In this study, multiple regression analysis-hierarchical regression analysis was used to examine the role of gender and level of gender in the relationship between ego function and resilience in university students. Multiple regression analysis is a type of analysis for estimating the dependent variable based on two or more arguments associated with the dependent variable. The hierarchical method in multiple regression analysis refers to analyzing the predictive variables in the order previously determined by the researcher and to evaluate each predictive variable in terms of the variance contributions to the dependent variable (Büyüköztürk et al., 2012). Confidence interval in analyses was determined as $95 \%$ (significance level $0.05 ; \mathrm{p}<0.05$ ).

\section{Results}

The findings of the study include descriptive statistics regarding scale and lower dimension scores first, and then findings on sub-problems. 


\subsection{Descriptive Statistics}

Table 1. Descriptive statistics

\begin{tabular}{|l|l|l|l|l|l|}
\hline Scale and Sub-dimensions & Min. & Max. & $\bar{X}$ & SS & Skewness \\
\hline Self-Perception & 1.00 & 5.00 & 2.36 & 0.87 & 0.29 \\
\hline Perception of the Future & 1.00 & 5.00 & 2.25 & 0.95 & 0.50 \\
\hline Structural Style & 1.00 & 5.00 & 2.51 & 1.01 & 0.40 \\
\hline Social Competence & 1.00 & 5.00 & 2.44 & 0.88 & 0.27 \\
\hline Family Harmony & 1.00 & 5.00 & 2.06 & 0.91 & 0.73 \\
\hline Social Resources & 1.00 & 5.00 & 1.97 & 0.71 & 0.54 \\
\hline Resilience & 1.00 & 5.00 & 2.26 & 0.60 & 0.29 \\
\hline Ability to Evaluate The Truth & 0.00 & 3.00 & 0.74 & 0.47 & 0.81 \\
\hline Judging & 0.00 & 3.00 & 1.05 & 0.42 & 0.74 \\
\hline Thinking Processes & 0.00 & 3.00 & 1.14 & 0.48 & 0.50 \\
\hline Creativity & 0.00 & 3.00 & 1.59 & 0.47 & 0.07 \\
\hline Sense of Reality & 0.00 & 3.00 & 0.91 & 0.52 & 0.73 \\
\hline Object Relationships & 0.00 & 3.00 & 1.09 & 0.43 & 0.63 \\
\hline Control of Instincts & 0.00 & 3.00 & 1.04 & 0.50 & 0.78 \\
\hline Functioning of Defenses & 0.00 & 3.00 & 1.10 & 0.51 & 0.68 \\
\hline Autonomous Functions & 0.00 & 3.00 & 1.13 & 0.49 & 0.82 \\
\hline Stimulant Threshold & 0.00 & 3.00 & 1.35 & 0.45 & 0.23 \\
\hline Synthesis Ability & 0.00 & 3.00 & 1.63 & 0.44 & -0.33 \\
\hline Dominance/Success & 0.00 & 3.00 & 1.69 & 0.48 & 0.09 \\
\hline
\end{tabular}

As shown in Table 1, the mean score from the adult resilience scale was found as $2.26 \pm 0.60$. Considering the lowest (1) and highest (5) scores that can be obtained from the scale, it can be suggested that the resilience of the students participating in the study was "low". When the sub-dimensions were examined, it was determined that the highest level of resilience of the students was "structural style" and "social competence".

The highest levels of ego functions in university students were found to be dominance/success $(1.69 \pm 0.48)$, synthesis ability (1.63 \pm 0.44$)$ and creativity (1.59 \pm 0.47$)$, respectively. It was determined that the lowest levels of ego functions observed were the ability to evaluate the truth $(0.74 \pm 0.47)$ and sense of reality $(0.91 \pm 0.52)$.

\subsection{Findings on Demographic Variables of the Study}

Results of t-test for independent samples applied to determine whether resilience and ego 
functions in young people varied in terms of gender are presented in Table 2.

Table 2. Differentiation of resilience and ego functions according to gender

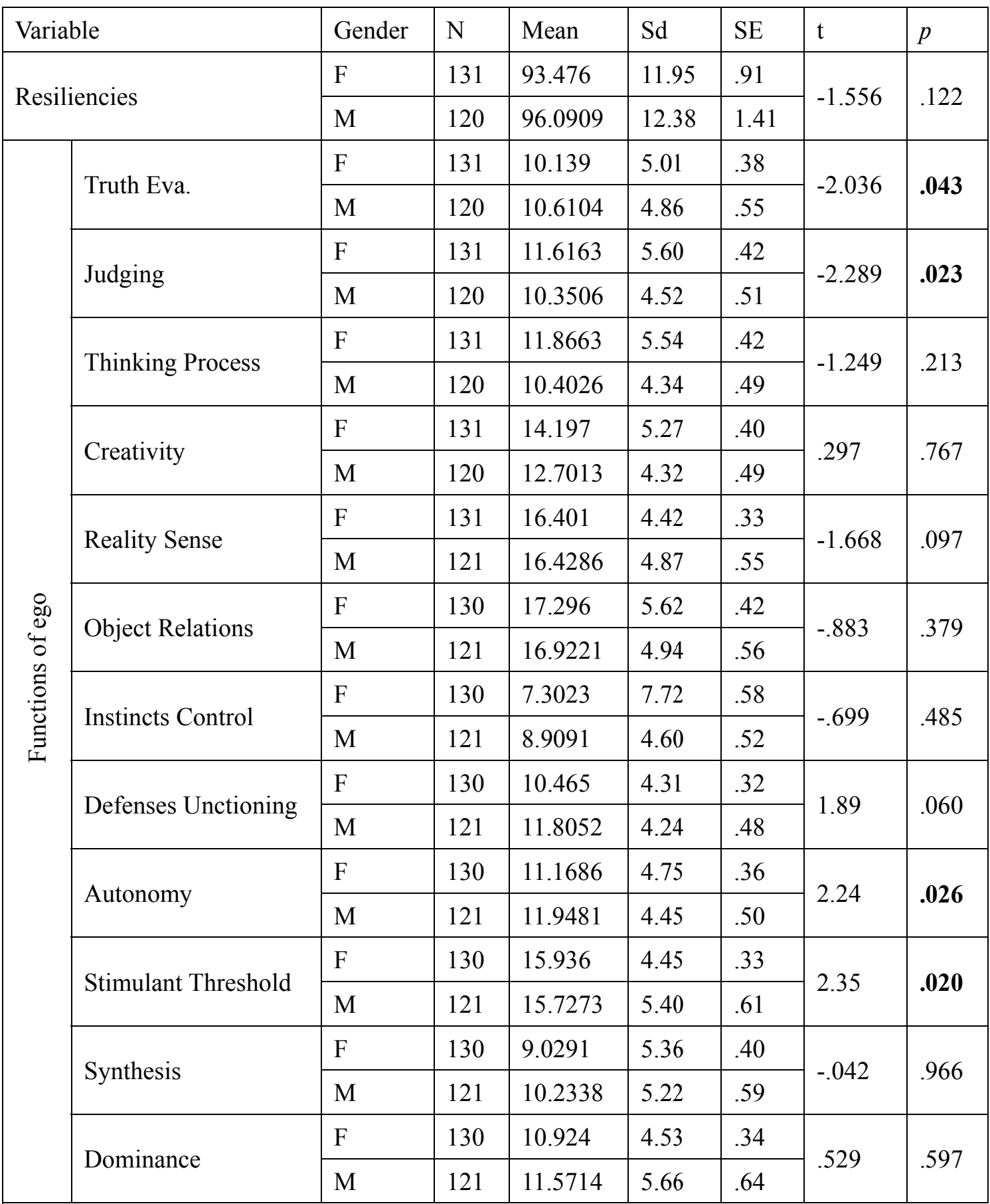

Note. $\mathrm{p}>.05(\mathrm{p}>.01), \mathrm{N}=251$.

As shown in Table 2, it was found that the difference in gender was significant on evaluating the truth, judging, autonomy and stimulant threshold which were among ego functions; while 
the evaluation of reality and autonomy were higher in men; stimulant threshold and judgment were found higher in women $(\mathrm{p}>.01)$.

Table 3 contains the results of correlation analysis on the relationship between independent and dependent variables.

Table 3. Correlation Analysis Results on the relationship between variables

\begin{tabular}{|c|c|c|c|c|c|c|c|}
\hline \multirow[b]{2}{*}{ Ego Functions } & \multicolumn{7}{|c|}{ Resilience Dimensions } \\
\hline & Self-Perception & $\begin{array}{l}\text { The Future } \\
\text { Perception }\end{array}$ & $\begin{array}{l}\text { Structural } \\
\text { Style }\end{array}$ & $\begin{array}{l}\text { Social } \\
\text { Competence }\end{array}$ & $\begin{array}{l}\text { Family } \\
\text { Harmony }\end{array}$ & $\begin{array}{l}\text { Social } \\
\text { Resources }\end{array}$ & Resilience \\
\hline $\begin{array}{l}\text { Ability to } \\
\text { Evalaute Truth }\end{array}$ & 0.04 & 0.08 & $0.14 *$ & $0.19 * *$ & $0.19 * *$ & $0.23 * *$ & $0.21 * *$ \\
\hline Judging & 0.00 & 0.04 & 0.11 & 0.04 & $0.13 *$ & $0.18 * *$ & 0.12 \\
\hline Thinking Processes & $0.21 * *$ & 0.11 & $0.20 * *$ & 0.12 & $0.23 * *$ & $0.16^{*}$ & $0.25 * *$ \\
\hline Creativity & $0.13 *$ & $0.16^{*}$ & $0.14^{*}$ & $0.21 * *$ & 0.07 & $0.14^{*}$ & $0.21 * *$ \\
\hline Sense of Reality & $0.16^{*}$ & 0.11 & $0.14^{*}$ & $0.14^{*}$ & $0.26^{* *}$ & $0.24 * *$ & $0.26^{* *}$ \\
\hline Object Relationships & $0.18 * *$ & $0.13 *$ & 0.08 & $0.14 *$ & $0.15 *$ & $0.22 * *$ & $0.22 * *$ \\
\hline Control of Instincts & $0.13 *$ & 0.07 & 0.11 & 0.05 & $0.18 * *$ & $0.19 * *$ & $0.18 * *$ \\
\hline $\begin{array}{l}\text { Functioning of } \\
\text { Defenses }\end{array}$ & $0.32 * *$ & $0.23 * *$ & $0.23 * *$ & $0.16^{*}$ & $0.21 * *$ & $0.15^{*}$ & $0.32 * *$ \\
\hline $\begin{array}{l}\text { Autonomous } \\
\text { Functions }\end{array}$ & $0.33 * *$ & $0.25 * *$ & $0.30 * *$ & $0.14^{*}$ & $0.22 * *$ & $0.15^{*}$ & $0.35 * *$ \\
\hline Stimulant Threshold & $0.14 *$ & 0.05 & 0.01 & $0.14^{*}$ & $0.13 *$ & 0.06 & $0.13 *$ \\
\hline Synthesis Ability & $0.39 * *$ & $0.39 * *$ & $0.41 * *$ & 0.11 & $0.24 * *$ & $0.23 * *$ & $0.45 * *$ \\
\hline $\begin{array}{l}\text { Dominance/ } \\
\text { Success }\end{array}$ & $0.41 * *$ & $0.38 * *$ & $0.41 * *$ & $0.16^{*}$ & $0.24 * *$ & $0.20 * *$ & $0.46^{* *}$ \\
\hline
\end{tabular}

Note. $* \mathrm{p}<0.05$.

As shown in Table 3, the relationship between ego functions and resilience is as follows according to the sub-dimensions:

(1) Positive and significant relationship was determined between the ability to evaluate the truth scores and scores from structural style $(\mathrm{r}=0.14)$, social competence $(\mathrm{r}=0.19)$, family harmony $(r=0.19)$, social resources $(r=0.23)$ and resilience $(r=0.21)$. Accordingly, students with a high ability to evaluate the truth have high scores of structural style, social competence, family harmony, social resources, and resilience. 
(2) Positive and significant relationship was determined between judgment scores and scores from family harmony $(r=0.13)$ and social resources $(r=0.18)$. Students with high levels of judgment have also a high level of family harmony and social resources.

(3) Positive and significant relationship was determined between thinking processes scores and scores from self-perception $(r=0.21)$, structural style $(r=0.20)$, family harmony $(r=0.23)$, social resources $(r=0.16)$ and resilience $(r=0.25 ; \mathrm{p}<0.05)$. Students with high thinking processes have high scores from self-perception, structural style, family harmony, social resources, and resilience.

(4) Positive and significant relationship was determined between creativity scores and scores from self-perception $(r=0.13)$, perception of future $(r=0.16)$, structural style $(r=0.14)$, social competence $(r=0.21)$, social resources $(r=0.14)$ and resilience $(r=0.21)$. Students with high levels of creativity also have higher scores in self-perception, future perception, structural style, social competence, social resources, and resilience.

(5) Positive and significant relationship was determined between sense of reality scores and scores from self-perception $(r=0.16)$, structural style $(r=0.14)$, social competence $(r=0.14)$, family harmony $(r=0.26)$, social resources $(r=0.24)$ and resilience $(r=0.26)$. Students with a high level of sense of reality have high scores from self-perception, structural style, social competence, family harmony, social resources, and resilience.

(6) Positive and significant relationship was determined between object relationship scores and scores from self-perception $(r=0.18)$, structural style $(r=0.13)$, social competence $(r=0.14)$, family harmony $(r=0.15)$, social resources $(r=0.22)$ and resilience $(r=0.22)$. Students with high object relationships have high scores from self-perception, structural style, social competence, family harmony, social resources, and resilience.

(7) Positive and significant relationship was determined between control of instincts scores and scores from self-perception $(r=0.135)$, family harmony $(r=0.18)$, social resources $(r=0.19)$ and resilience $(\mathrm{r}=0.18)$. Students with high control of instincts have high scores from self-perception, family harmony, social resources, and resilience.

(8) Positive and significant relationship was determined between functioning of defenses scores and scores from self-perception $(\mathrm{r}=0.32)$, perception of the future $(\mathrm{r}=0.23)$, structural style $(r=0.23)$, social competence $(r=0.16)$, family harmony $(r=0.21)$, social resources $(r=$ $0.15)$ and resilience $(r=0.32)$. Students with high functioning of defenses have high scores from self-perception, perception of the future, structural style, social competence, family harmony, social resources, and resilience.

(9) Positive and significant relationship was determined between autonomous functions scores and scores from self-perception $(\mathrm{r}=0.33)$, perception of the future $(\mathrm{r}=0.25)$, structural style $(\mathrm{r}$ $=0.30)$, social competence $(r=0.14)$, family harmony $(r=0.22)$, social resources $(r=0.15)$ and resilience $(\mathrm{r}=0.35)$. Students with high autonomous functions have high scores from self-perception, perception of the future, structural style, social competence, family harmony, social resources, and resilience. 


\section{Macrothink}

(10) Positive and significant relationship was determined between stimulant threshold scores and scores from self-perception $(\mathrm{r}=0.14)$, social competence $(\mathrm{r}=0.14)$, family harmony $(\mathrm{r}=$ $0.13)$ and resilience $(r=0.13)$. Students with high stimulant thresholds have high scores from self-perception, social competence, family harmony, and resilience.

(11) Positive and significant relationship was determined between synthesis ability scores and scores from self-perception $(\mathrm{r}=0.39)$, perception of the future $(\mathrm{r}=0.39)$, structural style $(\mathrm{r}=$ $0.41)$, family harmony $(r=0.24)$, social resources $(r=0.23)$ and resilience $(r=0.45)$. Students with high levels of synthesis ability also have higher scores in self-perception, future perception, structural style, social competence, social resources, and resilience.

(12) Positive and significant relationship was determined between dominance/success scores and scores from self-perception $(\mathrm{r}=0.41)$, perception of the future $(\mathrm{r}=0.38)$, structural style $(\mathrm{r}$ $=0.41)$, social competence $(r=0.16)$, family harmony $(r=0.24)$, social resources $(r=0.20)$ and resilience $(r=0.46)$. Students with high levels of dominance/success also have higher scores in self-perception, future perception, structural style, social competence, social resources and resilience $(\mathrm{p}<0.05)$.

Table 4 contains the results of the effect of ego functions on resilience and the role of gender and income level in this relationship. 
Table 4. Relationship between ego functions and resilience and the role of gender and income level variables in this relationship

\begin{tabular}{|c|c|c|c|c|c|c|}
\hline & Independent Variables & B & $\mathrm{SH}_{\mathrm{B}}$ & $\beta$ & $\mathrm{t}$ & $\mathrm{p}$ \\
\hline \multirow{14}{*}{$\begin{array}{l}\overline{0} \\
\bar{\delta} \\
\dot{\Sigma}\end{array}$} & Constant & 0.104 & 0.281 & & 0.372 & 0.710 \\
\hline & Ability to Evaluate Truth & 0.159 & 0.116 & 0.126 & 1.370 & 0.172 \\
\hline & Judging & 0.078 & 0.109 & 0.054 & 0.714 & 0.476 \\
\hline & Thinking Processes & 0.124 & 0.114 & 0.099 & 1.092 & 0.276 \\
\hline & Creativity & 0.091 & 0.089 & 0.072 & 1.018 & 0.310 \\
\hline & Sense of Reality & 0.206 & 0.114 & 0.179 & 1.800 & 0.073 \\
\hline & Object Relationships & 0.223 & 0.113 & 0.160 & 1.970 & 0.050 \\
\hline & Control of Instincts & 0.132 & 0.111 & 0.109 & 1.180 & 0.239 \\
\hline & Functioning of Defenses & 0.024 & 0.123 & 0.020 & 0.192 & 0.848 \\
\hline & Autonomous Functions & 0.246 & 0.102 & 0.200 & 2.397 & 0.017 \\
\hline & Stimulant Threshold & 0.020 & 0.091 & 0.015 & 0.217 & 0.829 \\
\hline & Synthesis Ability & 0.426 & 0.113 & 0.313 & 3.769 & 0.000 \\
\hline & Dominance/Success & 0.180 & 0.110 & 0.145 & 1.633 & 0.104 \\
\hline & \multicolumn{6}{|c|}{$R=0.592 ; R^{2}=0.350 ;$ Durbin Watson: $2.077 ; F_{(12238)}=10.681 ; p=0.000$} \\
\hline \multirow{16}{*}{$\begin{array}{l}\bar{\theta} \\
\bar{\delta} \\
\dot{\Sigma} \\
i\end{array}$} & Constant & 0.156 & 0.322 & & 0.484 & 0.629 \\
\hline & Ability to Evaluate Truth & 0.167 & 0.119 & 0.132 & 1.396 & 0.164 \\
\hline & Judging & 0.091 & 0.112 & 0.064 & 0.815 & 0.416 \\
\hline & Thinking Processes & 0.115 & 0.114 & 0.092 & 1.006 & 0.315 \\
\hline & Creativity & 0.095 & 0.090 & 0.075 & 1.064 & 0.289 \\
\hline & Sense of Reality & 0.207 & 0.115 & 0.180 & 1.808 & 0.072 \\
\hline & Object Relationships & 0.212 & 0.115 & 0.153 & 1.853 & 0.065 \\
\hline & Control of Instincts & 0.126 & 0.112 & 0.104 & 1.122 & 0.263 \\
\hline & Functioning of Defenses & 0.039 & 0.126 & 0.033 & 0.313 & 0.754 \\
\hline & Autonomous Functions & 0.253 & 0.104 & 0.206 & 2.440 & 0.015 \\
\hline & Stimulant Threshold & 0.008 & 0.093 & 0.006 & 0.087 & 0.931 \\
\hline & Synthesis Ability & 0.425 & 0.114 & 0.311 & 3.715 & 0.000 \\
\hline & Dominance/Success & 0.174 & 0.111 & 0.140 & 1.566 & 0.119 \\
\hline & Gender & 0.041 & 0.076 & 0.032 & 0.539 & 0.590 \\
\hline & Income level & 0.051 & 0.063 & 0.043 & 0.802 & 0.423 \\
\hline & \multicolumn{6}{|c|}{$\begin{array}{l}R=0.594 ; R^{2}=0.350 ; \text { Durbin Watson: } 2.077 ; \\
F_{(14 ; 236)}=9.175 ; p=0.000 ; \text { F Change } e_{(2 ; 236)}=0.399 ; p=0.646\end{array}$} \\
\hline
\end{tabular}

Note. Dependent variable: Resilience. 
As shown in Table 4, the first step of hierarchical regression analysis examines the effect of the independent variables of the study (ego functions) on the dependent variable, resilience. Accordingly, it can be seen that the first model installed is appropriate $\left(\mathrm{F}_{(12 ; 238)}=10.68 ; \mathrm{p}<\right.$ $0.05)$; there are no autocorrelation and multiple connections between dependent variables (Durbin Watson $<2.50$; Tolerance $>0.20$; VIF $<10$ ). Ego functions describe approximately $35 \%(\mathrm{R} 2=0.350)$ of the change in resilience. According to significance of standardized regression coefficients $(\beta)$ and coefficients in the first model, it was determined that autonomous functions $(\beta=0.20 ; \mathrm{t}=2.40 ; \mathrm{p}<0.05)$ and synthesis ability $(\beta=0.31 ; \mathrm{t}=3.77 ; \mathrm{p}$ $<0.05)$ variables had a positive and significant effect on resilience; other ego functions did not have significant effect on resilience $(\mathrm{p}>0.05)$.

It can be seen that the second model, in which gender and income level were are included, is appropriate $\left(\mathrm{F}_{(24 ; 236)}=9.17 ; \mathrm{p}<0.05\right)$; there are no autocorrelation and multiple connections between dependent variables (Durbin Watson $<2.50$; Tolerance $>0.20$; VIF $<10$ ). With the inclusion of gender and income level in the model, the rate of explanation for the variance in resilience was determined as $35 \%\left(\mathrm{R}^{2}=0.352\right)$. In the second model, it was determined that the variance difference described by the addition of gender and income level to the model was $0.002\left(1 . \mathrm{R}^{2}-2 . \mathrm{R}^{2}=0.002\right)$ and that this difference was not statistically significant $(\mathrm{F}$ change $\left._{(2 ; 236)}=0.44 ; \mathrm{p}>0.05\right)$. In other words, gender and income level have no role in the relationship between ego functions and psychological endurance.

\section{Discussion}

This research was conducted to examine the role of gender and income in the relationship between ego function and Resilience in young people. The findings obtained as a result of the analysis were discussed in the light of the literature in the order given in the sub-problems of the research.

Concerning the initial sub-problem of the study, it was examined whether there was a significant difference in resilience and ego functions according to gender, and consequently, it was determined that resilience did not vary significantly according to gender. While this finding appears to be similar to the results of some studies in the literature (Olsson \& Hwang, 2008; Sojo \& Guarino, 2011), on the other hand, there are also other studies with different results in favor of women (Friborg et al., 2003; Olsson et al., 2008). In another finding of the research concerning gender, it was found that the difference in gender was significant on evaluating the truth, judging, autonomy and stimulant threshold which were among ego functions; while the evaluation of reality and autonomy were higher in men; stimulant threshold and judgment were found higher in women. There was no gender difference in other sub-functions. It is seen that this finding may be important in explaining the variables affecting the development of the self. There are studies available in the literature in which variables for differentiation of ego functions are emphasized such as socio-economic level, socio-cultural factors (Güngör, 1998) and gender (Gander \& Gardiner, 2001). In this study, it is thought that gender differences in ego functions are significant in terms of the effect of gender roles. Indeed, the self is effective in the development process; one of the most important factors playing a role in the interpretation of self-knowledge and the establishment 
of the self is culture, and the self-concept also includes socio-cultural functions and values. Therefore, men and women participate in the same cultural life in different ways; gender-specific social roles that reflect cultural norms are effective in acquiring different skills and abilities. As in many cultures, women are more likely to raise children than men, care for family members and work in service-oriented specialist jobs, to provide social support to others and to maintain social relations in Turkey as in many cultures with dominant culture (Crossley, 2000; Gezici \& Güvenç, 2003). Therefore, the gender difference in ego functions seems to be descriptive in terms of gender.

In the second sub-problem of the study, it was examined whether there was a significant correlation between resilience and ego functions, and positive significant correlation was found between resilience, its sub-dimensions and assessing the truth, level of judgment, thinking processes, creativity, sense of reality, object relationships, harmony of instincts, functioning of defenses, autonomous functions, stimulant threshold, and synthesis ability. Accordingly, students with a high ability to evaluate the truth have high levels of structural style, social competence, family harmony, social resources, and resilience. Students with high levels of judgment have also a high level of family harmony and social resources. Students with high thinking processes have high levels of self-perception, structural style, family harmony, social resources, and resilience. Students with high levels of creativity also have higher levels of self-perception, future perception, structural style, social competence, social resources, and resilience. Students with a high level of sense of reality have high levels of self-perception, structural style, social competence, family harmony, social resources, and resilience. Students with high object relationships have high levels of self-perception, structural style, social competence, family harmony, social resources, and resilience. Students with a high harmony of instincts have high levels of self-perception, structural style, family harmony, social resources, and resilience. Students with high functioning of defenses have high levels of self-perception, perception of the future, structural style, social competence, family harmony, social resources, and resilience. Students with high autonomous functions have high levels of self-perception, perception of the future, structural style, social competence, family harmony, social resources, and resilience. Students with high stimulant thresholds have high levels of self-perception, social competence, family harmony, and resilience. Students with high synthesis ability have higher levels of self-perception, future perception, structural style, social competence, social resources, and resilience. Students with high dominance/success have higher levels of self-perception, future perception, structural style, social competence, social resources, and resilience. This finding shows that, as young people's ego functions increase positively, resilience also increases. Goldstein (1995) emphasized that ego functions are important for the adaptation of the individual to the outside world; he also indicates that ego functions and strengths and weaknesses of the individual, motivation and problem-solving capacity and his possibilities can be utilized. Ego functions give the person a sense of integrity and support the individual (Öztürk, 2001). The ego facilitates self-regulation and adaptation of conflicts between internal motivations and internal-external demands and integrates mental processes and experiences into a fully functional self (Auchincloss \& Samberg, 2012; Goldstein, 1995). It is considered important that the basic functions of the ego always serve the capacity to maintain a relationship with the 
outside world (Freud, 1974). In this context, it is seen that ego functions can contribute to indomitable as a positive adaptation process despite difficulties. It is apparent that psychological robustness, as a feature of high adaptation despite exposure or distress (Luthar, 2003), has a protective role, especially in the form of academic performance and mental health, in problems faced by university students either in their own lives or in their university lives, and resilience enables young people to get over negative situations by getting stronger; that is why this finding is important in terms of revealing the role of ego functions in this process.

In the finding of the third sub-problem of the study; ego functions explain about $35 \%$ of the change in resilience. Accordingly, ego functions significantly predict resilience. Freud explained ego functions in general as the ability of the self to protect the id and superego from internal and external dangers; this structure seems to have an effect on resilience as a structure that supports adaptation and emphasizes its capacity to cope under stress (Öztürk, 2001). Ego, in ego psychology, is focused in terms of development, level of functionality and treatment (Fleischer \& Lee, 2013), and the ego is defined by mental functions that determine how a person adapts to the world and handles internal conflicts. The defense function of the ego functions as a movement to try to reconcile one's instinctive demands with the demands of external reality. This shows that ego functions play an important role in terms of resilience, which is defined as a capacity for an individual to adapt to ever-changing environmental demands. Resilience is a structure that describes active interaction with the world, the repertoire of problem-solving strategies and integrated performance under stress (Farkas \& Orosz, 2015). Resilience refers to behaviorally positive, resilient and stressful situations (Luthar \& Zigler, 1991) with features that emphasize flexibility and general harmony of personality against ever-changing situations (Garmezy, 1990). In this respect, it is seen that ego functions and resilience can be treated as structures that support and strengthen the mental health of young people concerning each other.

Another finding of the study was that autonomy and synthesis capability variables from ego functions significantly predicted psychological soundness; it was determined that other ego functions did predict resilience at a significant level. In other words, autonomic functions and synthesis ability were found to have a positive and significant effect on resilience. Conflict in the autonomy function of the ego is described as the state of acting independently of effects and impulses. While emphasizing that autonomy is the "conflict-free" field of ego functioning; perception, intuition, comprehension, thinking, language, certain stages of motor development, learning and intelligence are in a circle free from this conflict. Each of these functions can only take place in a secondary conflict during development. Autonomy is closely related and even overlapping with the regulation and control of impulses, motives and reactions, and the ego coping with the impacts that hit it and performing its defensive function. While the synthesis function involves the ability and adaptation of individuals to regulate stimuli, it refers to the capacity to integrate various aspects of the functions of the ego and the cooperation of functions that belong to and do not belong to the ego. This function can also combine options to be the best solution for the individual in a specific situation, at a given time, or in a time frame. In addition to the capacity of this function to integrate into different experiences towards behavioral, psychological and action, it is 
emphasized that it is ready for human thoughts and movements with the ability to integrate these experiences physically and behaviorally (Bellak \& Meyers, 1975; Öztürk, 2001). Based on all these explanations, it may be useful to focus on the role of these ego functions in explaining resilience in young people, based on the finding that autonomy and synthesis functions positively affect resilience in young people.

In the other finding of the study, the role of gender and income level in the relationship between ego function and resilience in young people was examined, and the intermediary role of gender and income level was not found in the relationship between ego functions and resilience. Accordingly, it should be noted that the relationship between ego functions and resilience is a direct relationship, although gender and income level are not seen to have an intermediary effect in this relationship, this relationship is not a cause and effect relationship. In the literature, analyzing the studies discussing resilience according to gender and level; some studies demonstrate the effect of gender (Sezer \& Kezer, 2017; Terzi, 2008) and that have different findings (Campbell-Sills et al., 2009; Olsson et al., 2008). Furthermore, although income level does not have an intermediary role in the relationship between ego functions and resilience; there are studies in the literature suggesting that, as income and education levels increase, resilience also increases (Campbell-Sills et al., 2009). Besides, poverty is considered as a risk factor in terms of resilience (Gizir, 2004). In some studies, it was determined that income and education did not affect resilience (Olsson \& Hwang, 2008).

\section{Conclusion and Recommendations}

Consequently, when the findings of the study are evaluated in general, it may be useful to consider the ego functions obtained in the study as a variable in the development of effective intervention methods and increasing young individuals' resilience and thus their general wellbeing. That is because individuals with high resilience develop more positive influence, trust and psychological harmony (Block \& Kremen, 1996), at the same time, they can resist life difficulties and gain strength through supporting and maintaining positive mental development and positive life choices (Weissberg et al., 2003). Like everyone else in life, resilience (Masten, 2001) is crucial in creating social and emotional stability in young people who are facing or likely to face a period of catastrophe with the aim of complete academic success, psychosocial and professional development. Thus, it will be important to identify and develop factors responsible for individual capacities, such as resilience in regaining emotional balance to develop a better life in young people (Bernhard \& Pires, 2006).

The inclusion of young individuals in university senior grade and graduate status in this study creates a limitation in terms of generalizing the findings to other young individuals. For this reason, different sample groups can be studied in further studies. Especially, it may be good to do research with individuals who have income. On the other hand, the fact that the findings of this study are relational in their nature and they did not reveal cause and effect relationships can be considered as another limitation of this research. Therefore, it will be useful to carry out different experimental studies aimed at increasing resilience. 


\section{Macrothink}

\section{References}

Arastaman, G., \& Balc1, A. (2013). Investigation of high school students' resilience perceptions in terms of various variables. Educational Sciences: Theory \& Practice, 13(2), 915-928.

Auchincloss, E. L., \& Samberg, E. (2012). Psychoanalytic terms and concepts. New Haven, CT: Yale University Press.

Basım, H. N., \& Çetin, F. (2011). Reliability and Validity Study of the Psychological Resilience Scale for Adults. Turkish Journal of Psychiatry, 22(2), 104-14.

Belgrave, F. Z., Chase-Vaughn, G., Gray, F., Addison, J. D., \& Cherry, V. R. (2000). The effectiveness of a culture- and gender-specific intervention for increasing resiliency among African American preadolescent females. Journal of Black Psychology, 26(2), 133-147. https://doi.org/10.1177/0095798400026002001

Bellak, L., \& Meyers, B. (1975). Ego function assessment and analyzability. International Review of Psychoanalysis, 2, 413-427.

Bernard, M., \& Pires, D. (2006). Emotional Resilience in Children and Adolescence: Implications for Rational-Emotive Behavior Therapy. In A. Ellis \& M. E. Bernard (Eds.), Rational Emotive Behavioral Approaches to Childhood Disorders: Theory, Practice and Resear (p. 5). Springer, New York.

Block, J. (2002). Personality as an affect-processing system. Mahwah, NJ: Erlbaum. https://doi.org/10.4324/9781410602466

Block, J., \& Kremen, A. M. (1996). IQ and ego-resiliency: Conceptual and empirical connections and separateness. Journal of Personality and Social Psycholo, 70, 349-361. https://doi.org/10.1037/0022-3514.70.2.349

Büyüköztürk, Ş., Çakmak-Kılıç, E., Akgün, Ö. E., Karadeniz, Ş., \& Demirel, F. (2012). Scientific Research Methods (13th ed.). Ankara: Pegem Academy.

Campbell-Sills, L., Forde, D. R., \& Stein, M. B. (2009). Demographic and childhood environmental predictors of resilience in a community sample. Journal of Psychiatric Research, 43, 1007-1012. https://doi.org/10.1016/j.jpsychires.2009.01.013

Catalano, R. F., Berglund, M. L., Ryan, J. A. M., Lonczak, H. S., \& Hawkins, J. D. (2004). Positive youth development in the United States: research findings on evaluations of positive youth development programs. Annals of the American Academy of Political and Social Science, 591, 98-124. https://doi.org/10.1177/0002716203260102

Crossley, M. L. (2000). Introducing narrative psychology: Self, trauma and the construction of meaning (pp. 3-23). Buckingham: Open University Press.

Çevik, Y. (2013). Ego Function Assessment Questionnaire to Turkey Suitable Conditions Validity, Reliability Study (Doctoral Thesis, Marmara University Institute of Health Sciences. Istanbul). 


\section{Macrothink

Çiftçi Arıdağ, N, \& Ünsal Seydooğulları, S. (2019). Investigating life satisfaction and resiliency levels of high school students based on the relation with parental attitudes. Hacettepe University Journal of Education, 34(4), 1037-1060. https://doi.org/10.16986/ HUJE.2018038527

Erarslan, Ö. (2014). Investigation of Self-esteem, Positive World View and the Mediating Role of Hope in the Relationship Between Psychological Resilience and Depressive Symptoms and Life Satisfaction in University Students (Master Thesis, Hacettepe University. Ankara).

Farkas, D., \& Orosz, G. (2015). Ego-Resiliency Reloaded: A Three-Component Model of General Resiliency. PLoS ONE, 10(3). https://doi.org/10.1371/journal.pone.0120883

Fleischer, L., \& Lee, E. (2013). Ego Psychological Contributions to Understanding Psychopharmacology and Clinical Practice in Social Work Education. Smith College Studies in Social Work, 83(4), 446-465. https://doi.org/10.1080/00377317.2013.834760

Freud, A. (1986). Ego ve Savunma Mekanizmaları. İstanbul: Bağlam Yayıncılık.

Freud, S. (1974). Formulations on the two Principles of Mental Functioning. The Standard Edition of The London: Hogarth Press.

Freud, S. (1989). The social construction of normality. Families in Society, 80(4), 333-339. https://doi.org/10.1606/1044-3894.1213

Friborg, O., Hjemdal, O., Rosenvinge, J. H., \& Martinussen, M. (2003). A new rating scale for adult resilience: What are the central protective resources behind health adjustment? International Journal of Methods in Psychiatric Research, 12(2), 65-76. https://doi.org/ 10.1002/mpr.143

Gander, M. J., \& Gardiner, H. W. (2001). In B. Onur (Ed.), Child and Adolescent Development (4th ed.). Ankara: Image Bookstore.

Garmezy, N. (1990). In J. Rolf, A. S. Masten, D. Cicchetti, K. Nuechterlein, and S. Weintraub (Eds.), A Closing Note: Reflections on the Future, in Risk and Protective Factors in the Development of Psychopathology (pp. 527-534). Cambridge University Press, New York, USA. https://doi.org/10.1017/CBO9780511752872.030

Gezici, M., \& Güvenç, G. (2003). Comparison of Working Women and Housewives in terms of Self-Perception and Self-Editing. Turkish Journal of Psychology, 18(51), 1-14. http://doi.org/10.5539/res.v9n2p268

Gitterman, A. (1991). Social work practice with vulnerable populations. In A. Gitterman, (Ed.), Handbook of Social Work Practice with Vulnerable Populations (pp. 1-32). Columbia University Press, New York, NY, USA. https://doi.org/10.7312/gitt11396-002

Gizir, C. (2004). Academic resilience: An investigation of protective factors contributing to the academic achievement of eighth grade students in poverty (Unpublished doctoral dissertation, Middle East Technical University, Ankara). 


\section{MInstitute ${ }^{\text {Mnk }}$}

Goldstein, E. (1995). Ego psychology and social work practice (2nd ed.). New York, NY: The Free Press.

Güngör, D. (1998). Self complexity. Turkish Psychological Articles, 1(1), 81-92.

Gürgan, U. (2006). The effect of group counseling on the resilience levels of university students. Unpublished doctoral dissertation, Ankara University, Ankara.

Henderson, N., \& Milstein, M. M. (1996). Resiliency in Schools: Making It Happen for Students and Educators. Thousand Oaks, CA: Corwin Press.

Jerry, M. B. (2006). Personality. Kaknüs Publishing. Istanbul.

Kara1rmak, Ö. (2007). Investigation of personal qualities contributing to psychological resilience among earthquake survivors: A model testing study. Middle East Technical University, Institute of Social Sciences, Unpublished Doctoral Thesis, Ankara.

Karairmak, Ö., \& Siviş-Çetinkaya, R. (2011). The Effect of Self-Esteem and Locus of Control on Psychological Soundness: The Mediating Role of Emotions. Turkish Journal of Psychological Counseling and Guidance, 4(35), 30-43.

Karasar, N. (2013). Scientific Research Method (25th ed.). Ankara: Nobel Publishing.

Lee, J. H., Kim, A. R., Kim, B., Lee, M. Y., \& Lee, S. M. (2013). Resilience: A Meta-Analytic Approach. Journal of Counseling and Development, 91(3). https://doi.org/ 10.1080/00377317.2013.834760

Luthar S. S., \& Zigler, E. (1991). Vulnerability and competence: A review of research on resilience in childhood. American Journal of Orthopsychiatry, 61(1), 6-22. https://doi.org/ $10.1037 / \mathrm{h} 0079218$

Luthar, S. (2003). Resilience and vulnerability: Adaptation in the context of childhood diversities. New York: Cambridge. https://doi.org/10.1017/CBO9780511615788

Luthar, S. (2006). Resilience in development: A synthesis of research across five decades. In D. Cicchetti \& D. J. Cohen (Eds.), Developmental psychopathology: Risk, disorder, and adaptation (2nd ed., pp. 739-795). New York: Wiley. https://doi.org/10.1002/97804709 39406.ch20

Masten, A. S. (2001). Ordinary magic: Resilience processes in devellopment. American Psychologist, 56, 227-238. https://doi.org/10.1037/0003-066X.56.3.227

Masten, A. S., \& Cicchetti, D. (2012). Risk and resiliencepsychopathology: The legacy of Norman Garmezy. Development and Psychopathology, 24(2), 333-334. https://doi.org/ $10.1017 / \mathrm{S} 0954579412000016$

Masten, A. S., \& Obradovic, J. (2006). Competence and resilience in development, Annals of the NewYork Academy of Sciences, 1094, 13-27. https://doi.org/10.1196/annals.1376.003

Nolte, T., Guiney, J., Fonagy, P., Mayes, L. C., \& Luyten, P. (2011). Interpersonal stress regulation and the development of anxiety disorders: an attachment-based developmental 


\section{Macrothink}

framework. Frontiers in Behavioral Neuroscience, 5(55). https://doi.org/10.3389/fnbeh.2011. 00055

Olsson, M. B., \& Hwang, C. P. (2008). Socioeconomic and psychological variables as risk and protective factors for parental well-being in families of children with intellectual disabilities. Journal of Intellectual Disability Research, 52(12), 1102-1113. https://doi.org/ 10.1111/j.1365-2788.2008.01081.x

Olsson, M. B., Larsman, P., \& Hwang, P. C. (2008). Relationships among risk, sense of coherence, and wellbeing in parent of children with and without intellectual disabilities. Journal of Policy and Practice in Intellectual Disabilities, 5(4), 227-236. https://doi.org/ 10.1111/j.1741-1130.2008.00184.x

Orthner, D. K., Jones-Sanpei, H., \& Williamson, S. (2004). The Resilience and Strengths of Low-Income Families. Family Relations: Special Issue on Low-Income and Working-Poor Families, 53(2), 159-167. https://doi.org/10.1111/j.0022-2445.2004.00006.x

Öztürk, M. O. (2001). Mental Health and Disorders. Nobel Medical Books Publishing, Istanbul.

Philippe, F. L., Lecours, S., \& Beaulieu-Pelletier, G. (2009). Resilience and Positive Emotions: Examining the Role of Emotional Memories. Journal of Personality, 77(1). https://doi.org/10.1111/j.1467-6494.2008.00541.x

Reich, J. W. (2006). Three psychological principles of resilience in natural disasters. Disaster Prevention and Management: An International Journal, 15, 793-798. https://doi.org/10.1108/ 09653560610712739

Savi Çakar, F. (2018). The Role of Resilience and Gender in the Relationship between Adults' Childhood Traumatic Experiences and Psychological Symptoms. PAU Journal of Education, 44, 114-131. https://doi.org/10.9779/PUJE.2018.209

Seligman, M. E. (2011). Flourish: A visionary new understanding of happiness and well-being (1st Free Press Hardcover ed.). New York, NY: Free Press.

Sezer, S., \& Kezer, F. (2017). The Investigation of Candidate Teachers' Resilience and Hopelessness Levels. Kastamonu Education Journal, 25(2).

Sojo, V., \& Guarino, L. (2011). Mediated moderation or moderated mediation: relationship between length of unemployment, resilience, coping and health. The Spanish Journal of Psychology, 14(1), 272-281.https://doi.org/10.5209/rev_SJOP.2011.v14.n1.24

Southwick, S. M., Douglas-Palumberi, H., Pietrzak, R. H. Friedman, M. J., Resick, P. A., \& Keane, T. M. (2014). Resilience. Handbook of PTSD: Science and practice (2nd ed., pp. 590-606). New York: Guilford Press.

Spencer, M. B. (2006). Phenomenology and ecological systems theory: Development of diverse groups. In W. Damon \& R. M. Lerner (Eds.), Handbook of Child Psychology (6th ed., Vol. 1, pp. 829-893). John Wiley \& Sons, Hoboken, NJ, USA. 


\section{Macrothink}

Sun, J., \& Stewart, D. (2012). Age and Gender Effects on Resilience in Children and Adolescents. International Journal of Mental Health Promotion, 9(4), 16-25. https://doi.org/ 10.1080/14623730.2007.9721845

Terzi, Ş. (2008). The relationship between self-recovery power and internal protective factors in university students. Hacettepe University Faculty of Education Journal, 35, 297-306.

Terzi, S. (2013). The relationship between the psychological resilience and perceived social support of university students. Turkish Journal of Psychological Counseling and Guidance, 3(29), 1-11.

Tsarfati, H. (2017). Ego Functions, Defenses, and Countertransference: A Beginning School Social Work Student's Way to Professional and Personal Growth. International Journal of School Social Work, 2(1). https://doi.org/10.4148/2161-4148.1005

Tugade, M. M., \& Fredrickson, B. L. (2002). Positive emotions and emotional intelligence. In L. Feldman Barrett \& P. Salovey (Eds.), The wisdom of feelings (pp. 319-340). New York: Guilford.

Wang, J. (2009). A study of resiliency characteristics in the adjustment of international Graduate students at American universities. Jou of Studies in International Education, 13, 22-45. https://doi.org/10.1177/1028315307308139

Weissberg, R. P., Kumpfer, K. L., \& Seligman, M. E. P. (2003). Prevention that works for children and youth: An introduction. American Psychologist, 58, 425-432. https://doi.org/ 10.1037/0003-066X.58.6-7.425

Windle, M. (1999). Critical conceptual and measurement issues in the study of nresilience. In M. D. Glantz \& J. L. Johnson (Eds.), Resilience and development: Positive life adaptations (pp. 161-178). New York: Kluwer Academic/Plenum Publishers.

Yalım, D. (2007). First year college adjustment: The role of coping, ego-resiliency, optimism and gender (Unpublished Master's Thesis, Middle East Technical University, Ankara).

Zautra, A. J., Hall, J. S., \& Murray, K. E. (2010). Resilience: A new definition of health for people and communities. In J. W. Reich, A. J. Zautra, \& J. S. Hall (Eds.), Handbook of adult resilience (pp. 3-29). The Guilford Press.

\section{Copyright Disclaimer}

Copyright for this article is retained by the author(s), with first publication rights granted to the journal.

This is an open-access article distributed under the terms and conditions of the Creative Commons Attribution license (http://creativecommons.org/licenses/by/3.0/). 